\title{
Anal Squamous Intraepithelial Lesions and Condyloma in HIV-Infected Heterosexual Men, Homosexual Men and Women: Prevalence and Associated factors.
}

Laurent Abramowitz*, Dalila Benabderrahmane*, Philippe Ravaud ${ }^{+}$, Francine Walker ${ }^{\ddagger}$, Christophe Rioux ${ }^{\S}$, Christine Jestin", Elisabeth Bouvet $^{\S}$, Jean-Claude Soulé*, Catherine Leport $^{\|}$, Xavier Duval ${ }^{+, \| * *}$.

* AP-HP, Department of gastroenterology and proctology, Bichat hospital, Paris, France;

+ AP-HP, Department of biostatistics, Bichat university hospital, Paris, France; Paris 7 university, Paris, France.

$\ddagger$ AP-HP, Department of anatomopathology, Bichat hospital, Paris, France.

$\S$ AP-HP, Department of infectious and tropical diseases A, Bichat hospital, Paris, France; Paris 7 Denis Diderot University, Paris, France.

\| AP-HP, Department of infectious and tropical diseases B, Bichat hospital, Paris, France;

Paris 7 Denis Diderot University, Paris, France

** Inserm, Clinical Investigation Center 007; Inserm, U738, Bichat, Paris, France.

The authors have no commercial or other associations that might pose a conflict of interest

Total word count for the text of the manuscript: approximately 3250 words

Abstract: 240 words

Correspondence and reprint requests, at the following address:

Corresponding authors:

Dr Laurent Abramowitz

Service de Gastroentérologie

Hôpital universitaire Bichat Claude Bernard, 46 rue Henri Huchard,

75877 Paris, CEDEX 18, France

phone: (33) 140258716 fax: (33) 140258783

e-mail: laurent.abramowitz@bch.aphp.fr

Dr Xavier Duval

Service des maladies infectieuses et tropicales B

Hôpital universitaire Bichat Claude Bernard, 46 rue Henri Huchard,

75877 Paris, CEDEX 18, France

phone: (33) 140257803 fax: (33) 140258860

e-mail: xavier.duval@ bch.aphp.fr 


\section{Abstract : 240 words}

Objective: To assess the prevalence of and associated factors with squamous intraepithelial lesions and condyloma (HPV-related lesions) in HIV-infected patients.

Design: Cross-sectional study.

Setting: Tertiary care university hospital.

Patients: 516 consecutive outpatients.

Intervention: Systematic examination for macroscopic HPV-lesions through anoscopy with histological confirmation, evaluation of dysplasia and HPV typing. Sexual behaviours were assessed through a semi-directive questionnaire.

Main outcome measures: Perianal and endoanal HPV-lesions with and without histological dysplasia.

Results: Among 473 (92\%) examined patients, (200 homosexual men, 123 heterosexual men, 150 women), 108 (23\%) had histologically-confirmed anal HPV-lesions (36\%, $15 \%$ and 11\% of the respective populations), including 51 (47\%) with only endoanal localisation. Among these 108 patients, histological dysplasia of grades I or II and of grade III were noted respectively in 59 and 2 patients, invasive endoanal cancer in 1; 3 patients also had high-risk oncogenicity HPV without dysplasia. Independent identified associated factors of HPVrelated condyloma were number of incidents of sexual intercourse per month $(\mathrm{OR}=1.04 ; 95 \%$ CI: 1.01-1.06), CD4 cell count below $200 \times 10^{6}$ cells/L (OR=3.22; 95\% CI: 1.37-7.60), history of anal HPV-lesion $(\mathrm{OR}=4.57$; 95\% CI: 2.13-9.81), and receptive anal intercourse $(\mathrm{OR}=2.30 ; 95 \%$ CI: 1.11-4.77). These two latter factors remained associated with histological dysplasia $(\mathrm{OR}=2.82 ; 95 \% \mathrm{CI}: 1.38-5.76$ for history of anal condyloma, and $\mathrm{OR}=4.29 ; 95 \%$ CI: 2.18-8.44 for receptive anal intercourse).

Conclusions: The high rate of condyloma and histological dysplasia seen in this study argues for a systematic screening for these lesions in HIV-infected individuals.

Keywords: HIV, anal canal, Human papillomavirus, anal dysplasia, anal cancer, condyloma 


\section{INTRODUCTION}

The incidence of epidermoid anal cancer is reported to have increased in recent decades and may be even higher among HIV-positive men who have sex with men (MSM) [14]. There is strong evidence that anal squamous intraepithelial lesions (SIL) - the putative precursor lesion - and anal cancer are both linked to some Human Papillomavirus (HPV) infections $[4,5]$. Detection of anal HPV through molecular techniques is frequent in both HIV-infected MSM and women [4, 6], and to a lesser extent in HIV-negative individuals. In two recent reports, anal HPV was also detected in HIV-infected heterosexual males in the absence of anal intercourse [7, 8]. Similarly, detection of anal SIL through anal cytology samples is more frequent in HIV-positive MSM than in HIV-negative ones [9], and risk for progression from low-grade SIL toward high-grade SIL is higher in HIV-infected MSM than in HIV-negative MSM [10].

Since the second half of the 90's, highly active antiviral therapy (HAART) has dramatically decreased HIV morbidity and mortality. The effect of HAART on the incidence of anal cancer, precursor lesions and HPV prevalence can be complex and results reported in the literature are conflicting [11-13]. On the one hand, the induced immune recovery could reduce the prevalence of HPV infection, anal SIL and their evolution toward dysplasia; on the other hand, the increase in the sexual activity and lengthened survival associated with HAART may paradoxically lead to an opposite effect $[9,10,14]$.

Anal intraepithelial HPV infection may lead to different types of macroscopic lesions, depending on HPV types, with non-oncogenic HPV types leading to benign lesions usually named condyloma and oncongenic HPV types, such as types 16 and 18, leading to intraepithelial dysplasia. As HPV-induced anal dysplasia has been associated with an increased risk of anal cancer, it seemed important to us in the HAART era to determine the prevalence of these different types of macroscopic HPV-related anal lesions [1, 15]. 
We report here the results of a systematic screening for macroscopic anal HPV related lesions with a systematic search for intraepithelial dysplasia or cancer in a large population of HIV-infected individuals. Our objective was to determine the prevalence of these lesions (condyloma and intraepithelial dysplasia) in the HAART era in consecutive MSM, women and heterosexual men and to identify their risks factors. 


\section{METHODS}

\section{Patients and Study Design}

Beginning in May 2003 and during a 12-month period, screening for anal macroscopic HPV related lesion was systematically proposed by the primary care physician during a routine follow-up visit to a sample of HIV-infected outpatients in the infectious diseases units of Bichat Claude Bernard University hospital in Paris, France. The sample was composed of all consecutive patients consulting any of the medical doctors present during 3 randomlydetermined half-days per week. The 3 selected half-days were modified 3 times during the study period to allow for the screening of a representative sample of patients.

\section{Data Collected}

We collected the following data for each patient (whether they accepted screening or not): sex, age, geographic origin, risk factors for HIV infection, mean interval since the detection of HIV positive serostatus, worst Centers for Disease Control and Prevention stage of disease, CD4 cell nadir, CD4 cell count and HIV-RNA level at the time of the consultation as well as current antiretroviral therapy. In patients who refused the screening, the reason for the refusal was noted (lack of time, anal HPV-related lesion already monitored by a proctologist, unwillingness). In patients who accepted the screening, a standardized questionnaire was filled out after anal examination by the proctologist. This questionnaire asked for information regarding previous sexual transmitted diseases, history of genital and anal condyloma including the date and the type of the last treatment, and sexual activities and practices (anal sexual intercourse, frequency of acts of sexual intercourse per month, number of sexual partners per year, condom use). Men were considered to be homosexual or bisexual men if the reported HIV transmission risk factor was homosexuality or if they declared having receptive anal intercourse (hereafter referred to as homosexual men). 


\section{Anal Examination}

Anal examination was performed immediately following the HIV consultation in the infectious diseases unit by the same experienced proctologist (internal medicine physician with gastroenterology subspecialty training in proctology). The examination consisted in an ocular inspection (with and without aceto-white test which is considered to increase the visibility of HPV intra-epithelial lesions) of the anal margin (anal area visible before anoscopy examination) and an anal canal examination through anoscopy. Acetic acid was applied to the total area of anal margin and canal. HPV intra-epithelial lesion was suspected in case of either an acetowhite area or a slightly elevated mucosa resembling tumors white to pink in color or of exophytic elevated lesions easily distinguishable from normal mucosa. Biopsy was systematically performed to confirm the diagnosis of HPV related lesion. In the case of lesions found during the screening, patients were asked if they had any related discomfort. In males, external genital organs were also examined.

\section{Histological Analysis}

HPV intra-epithelial lesions were diagnosed by two independent observers using 4$\mu$ m-thick, paraffin-embedded sections of formalin-fixed tissue and stained with HES. Diagnosis was based on hyperpapillomatosis associated with hyperacanthosis and the presence of koilocytes. Low grade SIL, also called anal intraepithelial neoplasia of grade I-II (AIN 1 and 2) or low grade dysplasia, was defined as thickening of the squamous epithelium and slight (lower third) to moderate (lower half) architectural disruption with atypical cells but no atypical mitosis. High grade SIL also called anal intraepithelial neoplasia of grade III (AIN 3) or high grade dysplasia, was defined as loss of normal stratification of the cells, severe architectural disruption, and presence of atypical cytoplasm and nuclear features throughout the epithelium, particularly with atypical mitosis. Invasive squamous carcinoma was defined as tumor with extensive infiltration of the lamina propria by clusters of tumor 
cells having deeply invaded the anal wall $[1,16]$. Macroscopic HPV related lesions without dysplasia are hereafter referred to as "condyloma".

\section{In situ molecular techniques for detection of HPV}

In situ hybridization (ISH) was used for HPV screening and typing. For ISH, biotinylated and fluorescein isothiocyanate- labeled commercial genomic DNA probes were purchased from Argène (Varhiles, France) and Dakopatt (Glostrup, Denmark). ISH was performed according to our previously published protocol using probes specific to the various types of HPV: $6,11,16,18,31$ and 33 (1). When previous specific ISH were negative, ISH was performed using low (HPV 6/11) and high risk (16/18/31/33/35/39/45/51/52/56/58/59/ 68) probes (Dakopatt). It was amplified with the biotinyl-tyramide complex and the diaminobenzidine chromogen (Genpoint kit, Dakopatt). HPV detected by the high risk probe or the specific 16, 18, 31 or 33 probes were considered as being HPV type at high risk for oncogenicity.

\section{Statistical Analysis}

Patients were classified into three levels: patients with no HPV related lesions, patients with anal condyloma and patients with histological anal dysplasia. Thus, we used a polytomous logistic regression model to assess the association between categories of patients and characteristics of patients. Characteristics that were related to categories of patients in bivariate analysis were kept in the multivariate analysis with stepwise selection of the covariables. In bivariate analysis, qualitative variables were compared using chi-squared or Fisher's exact test, when appropriate, and quantitative variables were compared by analysis of variance. In multivariate analysis, the "patients with no lesions" category was the reference group. A significance level of 0.10 was required to include a variable in the model and a significance level of 0.05 was required for a variable to remain in the model. Odds ratios with 
a 95\% confidence interval (CI) were estimated. All statistical analyses were performed with SAS software, version 9.1 (SAS institute).

\section{Ethics}

All patients received written information before examination, and the local ethics committee approved the study. 


\section{RESULTS}

Anal examination was proposed to $516 \mathrm{HIV}$-infected patients, $473(92 \%)$ of whom accepted. Among the 43 patients who refused anal examination, 35 were male (11 homosexual and 24 heterosexual) and 8 female. The reasons for refusal included the following: known anal HPV intra-epithelial lesion already monitored by a proctologist (7 patients); lack of time (13 patients); unwillingness (23 patients). There was no difference in epidemiological data, CD4 cell count or nadir, plasmatic HIV-RNA value, CDC stage or percentage of HAART-receiving patients between the 473 patients who accepted and the 43 who refused the screening. The only difference observed was for injection drug addiction patients. Among the 43 patients who refused the screening, 10 (23\%) were IV-drug addicts whereas there were $37(8 \%)$ among the 473 who accepted $(p=0.003)$.

The characteristics of the 473 patients who accepted the screening are described in Table 1. The median age was 40 years (IQR 35-46); 28\% patients were at CDC stage C, median CD4 cell count was $454 \times 10^{6}$ cells/L (IQR 296-618), and 60\% of the patients had HIV-RNA below the limit of quantification (50 copies/ml). Twenty-four percent of the 473 patients reported having unprotected sexual intercourse and $18 \%$ of the women reported receptive anal intercourse.

Among the 473 patients, 108 (23\%) had macroscopic HPV-related lesion and 47\% of them (51/108) had only anal canal lesion (38/200 homosexual men, 8/123 heterosexual men and 5/150 women). The proportion of HPV-related lesion was $36.5 \%$ (73/200) among homosexual men, $14.6 \%(18 / 123)$ among heterosexual men and $11.3 \%(17 / 150)$ among women. Among the 108 patients with HPV related lesions, 47 had condyloma and 61 had histological dysplasia (13\% of the 473 patients) with low grade dysplasia (AIN 1-2) in 59 patients and high grade dysplasia (AIN 3) in 2 patients. Localisation of dysplasia between the anal margin and the anal canal is described in figure 1 . The repartition of dysplasia among the three populations was as follows: 42/200 homosexual men (21\%), 9/123 heterosexual men (7.3\%) and 10/150 women (6.7\%). High-risk oncogenicity HPV types were identified in 90\% 
of the 61 patients with dysplasia; 3 patients also had high-risk oncogenicity HPV without dysplasia. One invasive anal carcinoma was detected in one patient.

Seventy patients $(15 \%)$ had a previous history of anal condyloma, the last treatment of which had been performed on average 8 years ago. Seventy-seven percent of patients with anal HPV related lesion had no discomfort. Among the 473 screened patients, screening for anal HPV intra-epithelial lesion had been previously proposed to only $10(2.1 \%)$, of those 9 were homosexual and 1 was a woman. No patients had previously undergone anal cytology sampling.

Table 2 shows patients characteristics associated with anal condyloma or anal histological dysplasia among homo- or bisexual men, heterosexual men and women. Table 3 shows bivariate analysis of associated factors for anal condyloma and for anal histological dysplasia. Multivariate analysis for independent risk factors associated with anal condyloma and anal histological dysplasia, compared to patients with no anal lesions is displayed in Table 4. The number of incidents of sexual intercourse per month (OR=1.04; 95\% CI: 1.011.06), CD4 cell count below $200 \times 10^{6}$ cells/L (OR=3.22; 95\% CI: $\left.1.37-7.60\right)$, history of anal HPV related lesion $(\mathrm{OR}=4.57$; 95\% CI: 2.13-9.81), and receptive anal intercourse $(\mathrm{OR}=2.30$; 95\% CI: 1.11-4.77), were independently associated with anal condyloma, whereas only history of anal HPV related lesion $(\mathrm{OR}=2.82 ; 95 \% \mathrm{CI}: 1.38-5.76)$ and receptive anal intercourse ( $\mathrm{OR}=4.29 ; 95 \% \mathrm{CI}: 2.18-8.44)$ were associated with anal histological dysplasia. 


\section{DISCUSSION}

The systematic screening for anal macroscopic HPV related lesions conducted in this study on this large HIV-infected population during the HAART era revealed a high prevalence of anal condyloma (10\%) and histological dysplasia (13\%), of which half were exclusively endoanal. These findings concern not only the homosexual male population but also the heterosexual male population and the female population.

The comparison of the characteristics of this screened population with those of the population who refused the screening in this study shows that they were comparable except for the proportion of IV-drug addiction, which was a more frequent HIV transmission risk factor in the population of patients who refused the screening. The reason of the refusal in this population was essentially due to unwillingness. As the selected sample was randomly chosen, we assume that the studied population is representative of the whole population of HIV-infected outpatients seen in our hospital. One limitation of our study could be the referral bias of a large tertiary-care center. Because the study was conducted at a single center, we cannot exclude the possibility that geographic variation in the characteristics of the HIVinfected patients may have influenced the results. However, the characteristics of the HIVinfected patients seen in our hospital are comparable to those of patients seen in French hospitals based on the comparison of their characteristics using the DMI-2 software, in the French Hospital Data base on HIV.

The relation between anal condyloma considered as a benign lesion and anal histological dysplasia is very close as both diseases are linked to HPV infection and probably share transmission risk behaviours. A recent cohort study showed an incidence of anal intraepithelial neoplasia and anal cancer of 0.1/1000 patient/year in the HIV-infected population with anal condyloma [15]. Similarly, Frisch et al, in analysing risk factors for anal cancer in women, reported an odds ratio of 9.8 in women with a history of anal condyloma [3]. Looking specifically at associated factors of each disease may help understand the relation between these two types of anal HPV infection. 
There is no similar study in the literature performed before or during the HAART era to which our study could be compared as regards to the prevalence of histologically proved anal HPV infection. Our results could however be analysed in light of the prevalence of anal HPV shedding in the homosexual HIV infected men, which has been extensively studied. The presence of condyloma and anal histological dysplasia detected in the heterosexual male population without any history of anal intercourse, which has never previously been studied, is not surprising as, on the one hand, anal HPV shedding has been detected in heterosexual men in Piketty et al. study [7, 8], and on the other hand, husbands of women with cervical cancer have been found at an increased risk for anal cancer [17]. However, in the study of Piketty et al., the heterosexual male population with no history of anal intercourse was restricted to male injection drug users and therefore did not include all categories of heterosexuals [7]. Interestingly, the increase in the rate of HPV related lesions in HIVinfected homosexual patients as compared to heterosexual patients found in the present study (36.5\% vs $14.6 \%$ ) is consistent with the 2-fold higher rate of HPV detection reported in homosexual men as compared to heterosexual in a previous study (85\% versus 46\%) [7].

The prevalence of anal HPV related lesions (11.3\%) in our population of women is much higher than that reported in a previous study $(1,6 \%)$ [18]. The difference could be due to different reasons. First, it could be related to the examined anal region. In fact, Conley et al. looked only for anal margin localisation without looking for anal canal localisation. However, our prevalence remained higher when we did not take into account the $3 \%$ (5/150 women) of intra anal condyloma. Another reason may be the experience of the screening doctor. In our study, the examinations were performed by a senior proctologist, whereas they were performed by gynaecologists in the study of Conley et al. The prevalence we found in our study could not be overestimated because condyloma diagnosis in each case was based on histological result.

Multivariate analysis of risk factors associated with on the one hand condyloma and on the other hand anal histological dysplasia reveals both common but also distinct 
characteristics. In fact, neither virological (HIV-RNA) characteristics, CDC stage, geographic origins, length of known HIV positive serology, nor use of HAART were associated with the presence of anal condyloma or anal histological dysplasia. On the contrary, CD4 cell count below $200 \times 10^{6}$ cells/ $\mathrm{L}$ at the time of the screening was independently associated with the presence of condyloma whereas it was not for histological dysplasia. In the literature, there are conflicting data concerning the identification of CD4 cell count, CD4 nadir or current use of HAART as risk factors for HPV shedding or cytological dysplasia in homosexual men, heterosexual male injection drug users $[7,8,19]$ and in women $[4,13,18,20]$. Given our results, and given that other authors have studied only anal HPV shedding rather than HPV related histological lesions, we can hypothesise that immunity does not play the same role in controlling anal HPV shedding, benign anal HPV lesions (condyloma, related to nononcogenic HPV) development or anal dysplasia (related to oncogenic HPV) development.

History of anal condyloma was a strong predictor of the detection of both HPV related lesions (anal condyloma and histological dysplasia). Of note is that the time interval between the last treatment of previous anal condyloma lesion and the screening was rather long (average 8 years) and that the treatment dates back to the pre-HAART period in most patients. As the large majority of our patients were receiving HAART and were in virological success, we hypothesise that their immunological status improved between these two periods, but this improvement was not sufficient to prevent the recurrence of HPV-related lesions. Results are similar to those of recent studies in which no effect of HAART on HPV related lesions was observed $[13,21]$.

Sexual practices were also independently associated with anal HPV lesions, such as the number of incidents of sexual intercourse which has been previously reported to be associated with abnormal anal cytologic findings in homosexual men [7]. However, in our population, the independent association between anal HPV lesion and the number of incidents of sexual intercourse was significant for condyloma whereas it was only a trend for histological dysplasia. Receptive anal intercourse was a risk factor both for condyloma and 
histological dysplasia, which underlines the need to identify these sexual practices in women and bisexual men. However, as noted by others, the absence of anal intercourse cannot be used to rule out with certainty the presence of anal lesions or to systematically exclude such patients from a detection process $[4,7,8]$.

Histologically proved anal HPV lesions and/or high-risk HPV anal infection are thus frequent in this large population of HIV-infected patients including patients previously not considered to be at risk for anal cancer. Given their frequency and their potential relation to anal neoplasia, systematic screening should be considered. Whether this detection should concern the entire HIV-infected population or only those patients at highest risk of HPVrelated lesion has yet to be determined. The screening guidelines could differ between homosexual men, heterosexual men and women. These guidelines should also be implemented according to a criterion of cost-effectiveness. A pragmatic approach could be proposed: in homosexual men, the presence of HPV related lesion with histological sign of dysplasia in more than one fifth of patients suggests that this detection should include all homosexual HIV-infected men regardless of CD4 cell count or use of antiretrovirals, and especially in the case of frequent sexual activity and of history (even long past) of anal HPV lesions. In heterosexual men and in women, detection should probably focus on patients with a history of HPV-related diseases and previous mentioned at-risk behaviors. This screening should also be accompanied by prevention information to help reduce the rate of the at-risk behaviors for HPV exposure. 


\section{Acknowledgements:}

We are grateful to Dr Dominique Costagliola who gave us the opportunity to compare the characteristics of our patient population to those of patients included in the French data base on HIV and Gabriel Baron for his involvement in the statistical analyses. 


\section{References:}

1. Sobhani I, Vuagnat A, Walker F, et al. Prevalence of high-grade dysplasia and cancer in the anal canal in human papillomavirus-infected individuals. Gastroenterology 2001; 120:857-866.

2. Melbye M, Cote TR, Kessler L, Gail M, Biggar RJ. High incidence of anal cancer among AIDS patients. The AIDS/Cancer Working Group. Lancet 1994; 343:636-639.

3. Frisch M, Glimelius B, van den Brule AJ, et al. Sexually transmitted infection as a cause of anal cancer. $N$ Engl J Med 1997; 337:1350-1358.

4. Palefsky JM, Holly EA, Ralston ML, Da Costa M, Greenblatt RM. Prevalence and risk factors for anal human papillomavirus infection in human immunodeficiency virus (HIV)-positive and high-risk HIV-negative women. J Infect Dis 2001; 183:383391.

5. Bosch FX, Manos MM, Munoz N, et al. Prevalence of human papillomavirus in cervical cancer: a worldwide perspective. International biological study on cervical cancer (IBSCC) Study Group. J Natl Cancer Inst 1995; 87:796-802.

6. Palefsky JM, Holly EA, Ralston ML, Jay N. Prevalence and risk factors for human papillomavirus infection of the anal canal in human immunodeficiency virus (HIV)positive and HIV-negative homosexual men. J Infect Dis 1998; 177:361-367.

7. Piketty C, Darragh TM, Da Costa M, et al. High prevalence of anal human papillomavirus infection and anal cancer precursors among HIV-infected persons in the absence of anal intercourse. Ann Intern Med 2003; 138:453-459.

8. Wilkin TJ, Palmer S, Brudney KF, Chiasson MA, Wright TC. Anal intraepithelial neoplasia in heterosexual and homosexual HIV-positive men with access to antiretroviral therapy. J Infect Dis 2004; 190:1685-1691. 
9. Palefsky JM, Holly EA, Ralston ML, et al. Anal squamous intraepithelial lesions in HIV-positive and HIV-negative homosexual and bisexual men: prevalence and risk factors. J Acquir Immune Defic Syndr Hum Retrovirol 1998; 17:320-326.

10. Palefsky JM, Holly EA, Hogeboom CJ, et al. Virologic, immunologic, and clinical parameters in the incidence and progression of anal squamous intraepithelial lesions in HIV-positive and HIV-negative homosexual men. J Acquir Immune Defic Syndr Hum Retrovirol 1998; 17:314-319.

11. Delmas MC, Larsen C, van Benthem B, et al. Cervical squamous intraepithelial lesions in HIV-infected women: prevalence, incidence and regression. European Study Group on Natural History of HIV Infection in Women. AIDS 2000; 14:1775-1784.

12. Palefsky JM. Anal squamous intraepithelial lesions: relation to HIV and human papillomavirus infection. J Acquir Immune Defic Syndr 1999; 21:S42-48.

13. Lillo FB, Ferrari D, Veglia F, et al. Human papillomavirus infection and associated cervical disease in human immunodeficiency virus-infected women: effect of highly active antiretroviral therapy. J Infect Dis 2001; 184:547-551.

14. Palefsky JM, Holly EA, Ralston ML, Jay N, Berry JM, Darragh TM. High incidence of anal high-grade squamous intra-epithelial lesions among HIV-positive and HIVnegative homosexual and bisexual men. AIDS 1998; 12:495-503.

15. Sobhani I, Walker F, Roudot-Thoraval F, et al. Anal carcinoma: incidence and effect of cumulative infections. AIDS 2004; 18:1561-1569.

16. de Ruiter A, Carter P, Katz DR, et al. A comparison between cytology and histology to detect anal intraepithelial neoplasia. Genitourin Med 1994; 70:22-25.

17. Hemminki K, Dong C, Vaittinen P. Second primary cancer after in situ and invasive cervical cancer. Epidemiology 2000; 11:457-461.

18. Conley LJ, Ellerbrock TV, Bush TJ, Chiasson MA, Sawo D, Wright TC. HIV-1 infection and risk of vulvovaginal and perianal condylomata acuminata and intraepithelial neoplasia: a prospective cohort study. Lancet 2002; 359:108-113. 
19. Palefsky JM, Holly EA, Ralston ML, et al. Effect of highly active antiretroviral therapy on the natural history of anal squamous intraepithelial lesions and anal human papillomavirus infection. J Acquir Immune Defic Syndr 2001; 28:422-428.

20. Massad LS, Silverberg MJ, Springer G, et al. Effect of antiretroviral therapy on the incidence of genital warts and vulvar neoplasia among women with the human immunodeficiency virus. Am J Obstet Gynecol 2004; 190:1241-1248.

21. Gonzalez-Ruiz C, Heartfield W, Briggs B, Vukasin P, Beart RW. Anorectal pathology in HIV/AIDS-infected patients has not been impacted by highly active antiretroviral therapy. Dis Colon Rectum 2004; 47:1483-1486. 
Table 1: Characteristics of 473 HIV-infected patients who accepted the screening for anal HPV-related lesions.

\begin{tabular}{|c|c|c|c|c|c|}
\hline & $\begin{array}{l}\text { Total HIV population } \\
\qquad n=473\end{array}$ & $\begin{array}{l}\text { Homo or bisexual men } \\
\qquad \mathbf{n}=\mathbf{2 0 0}(42 \%)\end{array}$ & $\begin{array}{l}\text { Heterosexual men } \\
\qquad \mathbf{n}=123(26 \%)\end{array}$ & $\begin{array}{c}\text { Women } \\
\mathbf{n}=\mathbf{1 5 0}(\mathbf{3 2 \%})\end{array}$ & P-value \\
\hline Median age (IQR) & $40(35-46)$ & $41(36-46)$ & $42(37-48)$ & $37(33-42)$ & $<0.0001$ \\
\hline \multicolumn{6}{|l|}{ Geographic origins: } \\
\hline Europe, n (\%) & $229(48.4 \%)$ & $161(80.5 \%)$ & $39(31.7 \%)$ & $29(19.3 \%)$ & \\
\hline North Africa, n (\%) & $46(9.7 \%)$ & $6(3.0 \%)$ & $21(17.1 \%)$ & $19(12.7 \%)$ & \\
\hline Black Africa, n (\%) & $149(31.5 \%)$ & $6(3.0 \%)$ & $51(41.5 \%)$ & $92(61.3 \%)$ & \\
\hline West Indies, n (\%) & $22(4.6 \%)$ & $11(5.5 \%)$ & $6(4.9 \%)$ & $5(3.3 \%)$ & $<0.0001$ \\
\hline South America, n (\%) & $16(3.4 \%)$ & $13(6.5 \%)$ & 0 & $3(2.0 \%)$ & \\
\hline Asia, n (\%) & $11(2.3 \%)$ & $3(1.5 \%)$ & $6(4.9 \%)$ & $2(1.3 \%)$ & \\
\hline \multicolumn{6}{|l|}{ HIV transmission risk factors ${ }^{*}:$} \\
\hline Homosexuality, n (\%) & $192(40.6 \%)$ & - & - & - & \\
\hline Injection drug user, $\mathrm{n}(\%)$ & $37(7.8 \%)$ & $2(1.0 \%)$ & $21(17.1 \%)$ & $14(9.3 \%)$ & $<0.0001$ \\
\hline Heterosexuality, n (\%) & $215(45.4 \%)$ & - & - & - & \\
\hline Blood transfusion, n (\%) & $7(1.5 \%)$ & 0 & $3(2.4 \%)$ & $4(2.7 \%)$ & 0.0309 \\
\hline Unknown, n (\%) & $28(5.9 \%)$ & $1(0.5 \%)$ & $17(13.8 \%)$ & $10(6.7 \%)$ & $<0.0001$ \\
\hline Median length for known positive HIV serology, year (IQR) & $7.2(2.7-12.3)$ & $9.5(4.8-13.4)$ & $6.1(2.2-11.7)$ & $4.0(1.9-9.7)$ & $<0.0001$ \\
\hline CDC stage: A, n (\%): & $265(56.0 \%)$ & $108(54.0 \%)$ & $63(51.2 \%)$ & $94(62.7 \%)$ & \\
\hline $\mathrm{B}, \mathrm{n}(\%):$ & $77(16.3 \%)$ & $37(18.5 \%)$ & $18(14.6 \%)$ & $22(14.7 \%)$ & \\
\hline $\mathrm{C}, \mathrm{n}(\%)$ & $131(28 \%)$ & $55(27 \%)$ & $42(34 \%)$ & $34(23 \%)$ & \\
\hline Median nadir of $\mathrm{CD} 4+$ cell count $(\mathrm{IQR}), \times 10^{6}$ cells $/ \mathrm{L}$ & $196(68-318)$ & $231(79-338)$ & $127(62-260)$ & $203(90-327)$ & 0.0411 \\
\hline
\end{tabular}


Table 1: Characteristics of 473 HIV-infected patients who accepted the screening for anal HPV-related lesions.

\begin{tabular}{|c|c|c|c|c|c|}
\hline & $\begin{array}{l}\text { Total HIV population } \\
\qquad \begin{array}{l}n=473\end{array}\end{array}$ & $\begin{array}{l}\text { Homo or bisexual men } \\
\qquad \mathbf{n}=\mathbf{2 0 0}(42 \%)\end{array}$ & $\begin{array}{l}\text { Heterosexual men } \\
\qquad \mathrm{n}=\mathbf{1 2 3}(\mathbf{2 6 \%})\end{array}$ & $\begin{aligned} \text { Women } \\
\mathbf{n}=\mathbf{1 5 0}(\mathbf{3 2} \%)\end{aligned}$ & P-value \\
\hline Patients receiving antiretroviral therapy, $\mathrm{n}(\%)$ & $363(77 \%)$ & $167(83 \%)$ & $96(78 \%)$ & $100(67 \%)$ & 0.0010 \\
\hline Median CD4+ cell count (IQR), $\times 10^{6}$ cells/L & $454(296-618)$ & $533(365-707)$ & $380(220-553)$ & $410(288-584)$ & $<0.0001$ \\
\hline Patients with HIV-RNA level < $50 \log$ copies/ml, n (\%) & $284(60 \%)$ & $126(63 \%)$ & $75(61 \%)$ & $83(55 \%)$ & 0.3135 \\
\hline $\begin{array}{l}\text { Median plasma HIV-RNA level (IQR), log copies/ml (among patients } \\
\text { with HIV-RNA level > } 50 \log \text { copies } / \mathrm{ml} \text { ) }\end{array}$ & $3.9(2.6-4.8)$ & $3.6(2.4-4.9)$ & $4.1(2.8-4.8)$ & $3.9(2.9-4.8)$ & 0.6080 \\
\hline History of gonorrhoea, $\mathrm{n}(\%)$ & $141(30 \%)$ & $89(44 \%)$ & $40(33 \%)$ & $12(8 \%)$ & $<0.0001$ \\
\hline History of syphilis, n (\%) & $76(16 \%)$ & $56(28 \%)$ & $10(8 \%)$ & $10(7 \%)$ & $<0.0001$ \\
\hline \multicolumn{6}{|l|}{ Sexual practice ${ }^{\dagger}$ : } \\
\hline Median number of acts of sexual intercourse during a month, (IQR) & $3(0-8)$ & $5(1-10)$ & $3(0-8)$ & $1(0-4)$ & $<0.0001$ \\
\hline Median number of sexual partners during a year, $n$ (IQR) & $1(0-2)$ & $2(1-10)$ & $1(1-1)$ & $1(0-1)$ & $<0.0001$ \\
\hline Unprotected sexual intercourse n (\%) & $104 / 432(24 \%)$ & $51(28 \%)$ & $16(15 \%)$ & $37(28 \%)$ & 0.0329 \\
\hline Receptive anal intercourse, $\mathrm{n}(\%)$ & $227 / 473(48 \%)$ & $200(100 \%)$ & $0(0 \%)$ & $27(18 \%)$ & \\
\hline
\end{tabular}

IQR : Interquartil range $(25-75 \%)$

* Six patients had two HIV-transmission risk factors (4 with heterosexuality and injection drug user and 2 with heterosexuality and blood transfusion).

${ }^{+}$Information obtained in $91 \%$ patients. 
Table 2: Patients characteristics according to the detection of anal condyloma or anal histological dysplasia among homo or bisexual men, heterosexual men and women in the $473 \mathrm{HIV}$-infected patients who accepted the screening.

\begin{tabular}{|c|c|c|c|c|c|c|c|c|c|}
\hline & \multicolumn{3}{|c|}{ Homo or bisexual men } & \multicolumn{3}{|c|}{ Heterosexual men } & \multicolumn{3}{|c|}{ Women } \\
\hline & No lesion & Anal condyloma & Anal Dysplasia & No lesion & Anal condyloma & Anal Dysplasia & No lesion & Anal condyloma & Anal Dysplasia \\
\hline & $\mathrm{n}=127$ & $\mathrm{n}=31$ & $\mathrm{n}=42$ & $\mathrm{n}=105$ & $\mathrm{n}=9$ & $\mathrm{n}=9$ & $\mathrm{n}=133$ & $\mathrm{n}=7$ & $\mathrm{n}=10$ \\
\hline \multicolumn{10}{|l|}{ Geographic origins } \\
\hline Europe & $105 / 127(83 \%)$ & $25 / 31(81 \%)$ & $31 / 42(74 \%)$ & $30 / 105(29 \%)$ & $3 / 9(33 \%)$ & $6 / 9(67 \%)$ & $25 / 133(19 \%)$ & $1 / 7(14 \%)$ & $3 / 10(30 \%)$ \\
\hline Black Africa & $5 / 127(4 \%)$ & $0 / 31(0 \%)$ & $1 / 42(2 \%)$ & $49 / 105(47 \%)$ & $2 / 9(22 \%)$ & $0 / 9(0 \%)$ & $83 / 133(62 \%)$ & $3 / 7(43 \%)$ & $6 / 10(60 \%)$ \\
\hline Other & $15 / 127(12 \%)$ & $5 / 31(16 \%)$ & $7 / 42(17 \%)$ & $11 / 105(10 \%)$ & $1 / 9(11 \%)$ & $0 / 9(0 \%)$ & $7 / 133(5 \%)$ & $2 / 7(29 \%)$ & $1 / 10(10 \%)$ \\
\hline Positive HIV serology $>10$ years & $59 / 127(46 \%)$ & $16 / 31(52 \%)$ & $20 / 42(48 \%)$ & $32 / 105(30 \%)$ & $2 / 9(22 \%)$ & $4 / 9(44 \%)$ & $31 / 133(23 \%)$ & $3 / 7(43 \%)$ & $3 / 10(30 \%)$ \\
\hline$>5$ and $<10$ years & $39 / 127(31 \%)$ & $4 / 31(13 \%)$ & $9 / 42(21 \%)$ & $26 / 105(25 \%)$ & $4 / 9(44 \%)$ & $3 / 9(33 \%)$ & $26 / 133(20 \%)$ & $1 / 7(14 \%)$ & $2 / 10(20 \%)$ \\
\hline$<5$ years & $29 / 127(23 \%)$ & $11 / 31(35 \%)$ & $13 / 42(31 \%)$ & $47 / 105(45 \%)$ & $3 / 9(33 \%)$ & $2 / 9(22 \%)$ & $76 / 133(57 \%)$ & $3 / 7(43 \%)$ & $5 / 10(50 \%)$ \\
\hline Previous AIDS-defining event & $39 / 127(31 \%)$ & $9 / 31(29 \%)$ & $7 / 42(17 \%)$ & $33 / 105(31 \%)$ & $5 / 9(56 \%)$ & $4 / 9(44 \%)$ & $28 / 133(21 \%)$ & $2 / 7(29 \%)$ & $4 / 10(40 \%)$ \\
\hline Nadir CD4+ cell count $<200 \times 10^{6}$ cells $/ \mathrm{L}$ & $55 / 126(44 \%)$ & $14 / 31(45 \%)$ & $17 / 41(41 \%)$ & $65 / 104(63 \%)$ & $7 / 9(78 \%)$ & $7 / 9(78 \%)$ & $63 / 133(47 \%)$ & $6 / 7(86 \%)$ & $6 / 10(60 \%)$ \\
\hline Patient receiving anti-retroviral therapy & $107 / 127(84 \%)$ & $26 / 31(84 \%)$ & $34 / 42(81 \%)$ & $84 / 105(80 \%)$ & $5 / 9(56 \%)$ & $7 / 9(78 \%)$ & $91 / 133(68 \%)$ & $5 / 7(71 \%)$ & $4 / 10(40 \%)$ \\
\hline CD4+ cell count $\quad<200 \times 10^{6}$ cells $/ \mathrm{L}$ & $7 / 127(6 \%)$ & $3 / 31(10 \%)$ & $4 / 42(10 \%)$ & $17 / 105(16 \%)$ & $6 / 9(67 \%)$ & $2 / 9(22 \%)$ & $16 / 133(12 \%)$ & $3 / 7(43 \%)$ & $2 / 10(20 \%)$ \\
\hline Patients with HIV-RNA < $50 \log$ copies $/ \mathrm{ml}$ & $81 / 126(64 \%)$ & $16 / 31(52 \%)$ & 29/42 (69\%) & $66 / 105(63 \%)$ & $5 / 9(56 \%)$ & $4 / 9(44 \%)$ & $77 / 133(58 \%)$ & $3 / 7(43 \%)$ & $3 / 10(30 \%)$ \\
\hline
\end{tabular}


Table 2: Patients characteristics according to the detection of anal condyloma or anal histological dysplasia among homo or bisexual men, heterosexual men and women in the $473 \mathrm{HIV}$-infected patients who accepted the screening.

\begin{tabular}{|c|c|c|c|c|c|c|c|c|c|}
\hline & \multicolumn{3}{|c|}{ Homo or bisexual men } & \multicolumn{3}{|c|}{ Heterosexual men } & \multicolumn{3}{|c|}{ Women } \\
\hline & No lesion & Anal condyloma & Anal Dysplasia & No lesion & Anal condyloma & Anal Dysplasia & No lesion & Anal condyloma & Anal Dysplasia \\
\hline & $\mathrm{n}=127$ & $\mathrm{n}=31$ & $\mathrm{n}=42$ & $\mathrm{n}=105$ & $\mathrm{n}=9$ & $\mathrm{n}=9$ & $n=133$ & $\mathrm{n}=7$ & $\mathrm{n}=10$ \\
\hline History of anal condyloma & $29 / 127(23 \%)$ & $11 / 31(35 \%)$ & $16 / 42(38 \%)$ & $1 / 104(1 \%)$ & $3 / 9(33 \%)$ & $0 / 9(0 \%)$ & $5 / 133(4 \%)$ & $2 / 7(29 \%)$ & $3 / 10(30 \%)$ \\
\hline History of genital HPV related lesion & $12 / 127(9 \%)$ & $2 / 31(6 \%)$ & $2 / 42(5 \%)$ & $1 / 104(1 \%)$ & $2 / 9(22 \%)$ & $1 / 9(11 \%)$ & $13 / 133(10 \%)$ & $1 / 7(14 \%)$ & $5 / 10(50 \%)$ \\
\hline History of gonorrhoea or syphilis & $75 / 127(59 \%)$ & $13 / 31(42 \%)$ & $20 / 42(48 \%)$ & $36 / 105(34 \%)$ & $4 / 9(44 \%)$ & $2 / 9(22 \%)$ & $15 / 133(11 \%)$ & $2 / 7(29 \%)$ & $0 / 10(0 \%)$ \\
\hline $\begin{array}{l}\text { Median number of acts of sexual } \\
\text { intercourse during a month (IQR) }\end{array}$ & $4(1-9)$ & $4(1-15)$ & $6(2-10)$ & $3(0-7)$ & $8(1-12)$ & $1(0-5)$ & $1(0-4)$ & $3(0-20))$ & $0.5(0-2)$ \\
\hline $\begin{array}{l}\text { Median number of sexual partners during a } \\
\text { year (IQR) }\end{array}$ & $1(1-10)$ & $5(1-50)$ & $4(1-10)$ & $1(1-1)$ & $1(1-1)$ & $1(1-1)$ & $1(0-1)$ & $1(0-1)$ & $1(0-1)$ \\
\hline Receptive anal intercourse & $\begin{array}{l}127 / 127 \\
(100 \%)\end{array}$ & $31 / 31(100 \%)$ & $42 / 42(100 \%)$ & 0 & 0 & 0 & $20 / 122(16 \%)$ & $2 / 5(40 \%)$ & $5 / 8(62 \%)$ \\
\hline
\end{tabular}

Note: Number of patients (\% or IQR); IQR Interquartil range $(25 \%-75 \%)$ 
Table 3: Bivariate analysis among 3 categories of patients : without anal lesion, with anal condyloma and with histological anal dysplasia.

\begin{tabular}{|c|c|c|c|c|}
\hline & $\begin{array}{l}\text { Patients with } \\
\text { no anal lesion }\end{array}$ & $\begin{array}{l}\text { Patients with } \\
\text { anal condyloma }\end{array}$ & $\begin{array}{c}\text { Patients with } \\
\text { histological anal dysplasia }\end{array}$ & P Value \\
\hline \multicolumn{5}{|l|}{ Geographic origins } \\
\hline Europe & $160 / 365(44 \%)$ & $29 / 47(61 \%)$ & $40 / 61(66 \%)$ & \\
\hline North Africa & $35 / 365(10 \%)$ & $5 / 47(11 \%)$ & $6 / 61(10 \%)$ & \\
\hline Black Africa & $137 / 365(37 \%)$ & $5 / 47(11 \%)$ & $7 / 61(11 \%)$ & $<0.0001$ \\
\hline Other & $33 / 365(9 \%)$ & $8 / 47(17 \%)$ & $8 / 61(13 \%)$ & \\
\hline \multicolumn{5}{|l|}{ Positive HIV serology } \\
\hline$>10$ years & $122 / 365(33 \%)$ & $21 / 47(45 \%)$ & $27 / 61(44 \%)$ & \\
\hline$>5$ and $<10$ years & $91 / 365(25 \%)$ & $9 / 47(19 \%)$ & $14 / 61(23 \%)$ & \multirow{2}{*}{0.3255} \\
\hline$<5$ years & $152 / 365(42 \%)$ & $17 / 47(36 \%)$ & $20 / 61(33 \%)$ & \\
\hline Previous AIDS-defining event & $100 / 365(27 \%)$ & $16 / 47(34 \%)$ & $15 / 61(25 \%)$ & 0.5423 \\
\hline Nadir CD4+ cell count $<200 \times 10^{6}$ cells $/ \mathrm{L}$ & $183 / 363(50 \%)$ & $27 / 47(57 \%)$ & $30 / 60(50 \%$ & 0.6521 \\
\hline \multicolumn{4}{|l|}{ Patient receiving anti-retroviral therapy } & 0.8364 \\
\hline CD4+ cell count $<200 \times 10^{6}$ cells $/ \mathrm{L}$ & $40 / 365(11 \%)$ & $12 / 46(26 \%)$ & $8 / 61(13 \%)$ & 0.0184 \\
\hline Patients with HIV-RNA level < 50 log copies/ml & $224 / 364(62 \%)$ & $24 / 47(51 \%)$ & $36 / 61(59 \%)$ & 0.3782 \\
\hline History of anal condyloma & $35 / 364(10 \%)$ & $16 / 47(34 \%)$ & $19 / 61(31 \%)$ & $<0.0001$ \\
\hline
\end{tabular}




\begin{tabular}{|c|c|c|c|c|}
\hline & Patients with & Patients with & Patients with & \\
\hline & no anal lesion & anal condyloma & histological anal dysplasia & \\
\hline History of genital HPV- related lesion & $26 / 364(7 \%)$ & $5 / 47(11 \%)$ & $8 / 61(13 \%)$ & 0.2409 \\
\hline History of gonorrhoea or syphilis & $126 / 365(35 \%)$ & $19 / 47(40 \%)$ & $22 / 61(36 \%)$ & 0.7213 \\
\hline Median number of acts of sexual intercourse during a month (IQR) & $2(0-8)$ & $4(1-12)$ & $4(1-10)$ & $<0.0001$ \\
\hline Median number of sexual partners during a year (IQR) & $1(0-1)$ & $1(1-10)$ & $1(1-10)$ & $<0.0026$ \\
\hline Unprotected sexual intercourse & $77 / 334(23 \%)$ & $13 / 44(30 \%)$ & $14 / 54(26 \%)$ & 0.6029 \\
\hline Receptive anal intercourse & $112 / 339(33 \%)$ & $27 / 44(61 \%)$ & $39 / 54(72 \%)$ & $<0.0001$ \\
\hline Homo or bisexual men & $127 / 365(35 \%)$ & $31 / 47(66 \%)$ & 42/61 (69\%) & \\
\hline Heterosexual men & $105 / 365(29 \%)$ & 9/47 (19\%) & $9 / 61(15 \%)$ & \\
\hline Women & $133 / 365(36 \%)$ & $7 / 47(15 \%)$ & $10 / 61(16 \%)$ & \\
\hline
\end{tabular}


Table 4: Associated factors for anal condyloma and anal histological dysplasia in 473 HIV-infected individuals (Multivariate analysis).

\begin{tabular}{|c|c|c|c|c|}
\hline & \multicolumn{2}{|l|}{ Anal condyloma } & \multicolumn{2}{|c|}{ Histological anal dysplasia } \\
\hline & $\begin{array}{c}\text { Odds Ratio }{ }^{*} \\
(95 \% \text { confidence interval })\end{array}$ & P Value & $\begin{array}{c}\text { Odds Ratio }{ }^{*} \\
(95 \% \text { confidence interval })\end{array}$ & P Value \\
\hline CD $4+$ cell count $<200 \times 10^{6}$ cells $/ \mathrm{L}($ versus $>200)$ & $3.22(1.37-7.60)$ & 0.007 & $1.74(0.70-4.38)$ & 0.235 \\
\hline Receptive anal intercourse (yes versus no) & $2.30(1.11-4.77)$ & 0.026 & $4.29(2.18-8.44)$ & $<0.001$ \\
\hline History of anal condyloma (yes versus no) & $4.57(2.13-9.81)$ & $<0.001$ & $2.82(1.38-5.76)$ & 0.004 \\
\hline $\begin{array}{l}\text { Number of incidents of sexual intercourse per month } \\
\text { (for each additional incident) }\end{array}$ & $1.04(1.01-1.06)$ & 0.003 & $1.02(0.99-1.04)$ & 0.144 \\
\hline
\end{tabular}




\section{Figure 1:}

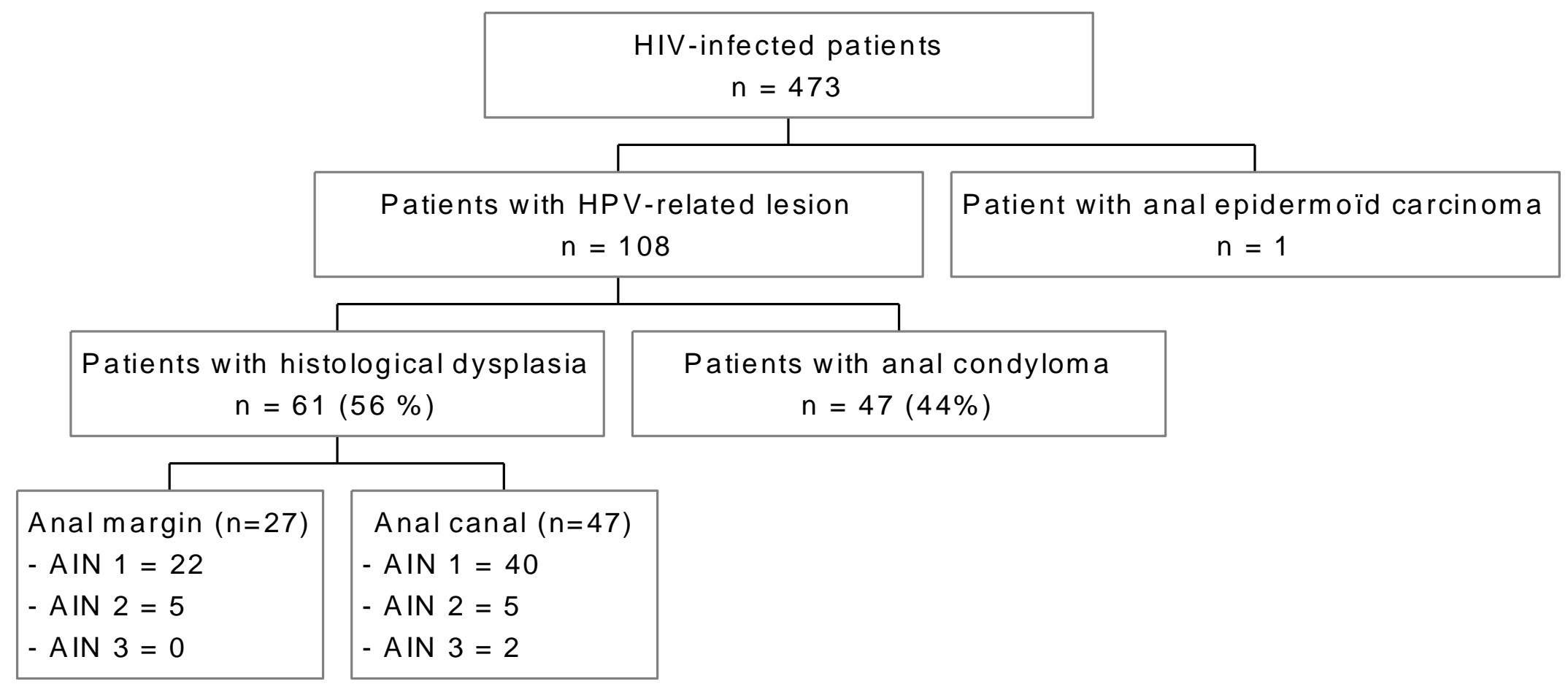

AIN: anal intraepithelial neoplasia of grade I-II (AIN 1 and 2) or Low grade dysplasia AIN 3: anal intraepithelial neoplasia of grade III or High grade dysplasia 
Figures' legends:

Figure 1: Number of patients with anal intraepithelial neoplasia according to the localisation of the dysplasia on anal margin or on anal canal in the $473 \mathrm{HIV}$-infected patients who accepted the screening. 